\title{
A rare cause of cyanosis: Congenital methemoglobinemia
}

\author{
RAHMA GUEDRI ${ }^{1}$, Nada Missaoui ${ }^{1}$, Leila ESSADDAM ${ }^{2}$, and SAAYDA Ben Becher ${ }^{1}$ \\ ${ }^{1}$ University of Tunis El Manar Faculty of Medicine of Tunis \\ ${ }^{2}$ Affiliation not available
}

February 13, 2021

\begin{abstract}
A 13-month-old infant, born from a consanguineous marriage. She presented isolated cyanosis. Physical examination was normal. Pulsed oxygen saturation was $94 \%$ in room air. Methemoglobin level was $39.4 \%$. The diagnosis of congenital methemoglobinemia type I was retained. She was successfully treated with methylene blue infusions and ascobic acid.
\end{abstract}

\section{A rare cause of cyanosis: Congenital methemoglobinemia}

Rahma Guedri, Nada Missaoui*, Leila Essaddam, Saayda Ben Becher

Faculty of Medicine of Tunis, University of Tunis El Manar; Children Hospital Bechir Hamza of Tunis, Department of Pediatrics (PUC), Tunis Jebbari, Tunis, Tunisia

* : Faculty of Medicine of Tunis, University of Tunis El Manar; Children Hospital Bechir Hamza of Tunis, Department of Pediatrics C, Tunis Jebbari, Tunis, Tunisia

\section{Introduction:}

Methemoglobinemia is a condition due to the presence in the blood of a methemoglobin level greater than $1 \%$. In methemoglobin, ferrous iron $\left(\mathrm{Fe}^{++}\right)$is oxidized to the ferric state $\left(\mathrm{Fe}^{+++}\right)$, resulting in tissue hypoxia. Methemoglobinemia can be acquired or, more rarely, congenital. Cyanosis is the most common symptom that suggests cardiac origin in the first place. In this article, we report a case of congenital methemoglobinemia in a 13-month-old tunisian girl.

Observation:Our patient is a 13-month-old girl, the first child of a first-degree consanguineous couple. The pregnancy was without complications. She was born at full term from vaginal delivery. Apgar's score was 9 at one minute and 10 at five minutes. Birth weight was 3300 grams. Since birth, parents noticed a cyanosis of the face that became more marked at the age of 5 months. Psychomotor development was normal. The infant was referred to our department by a general practitioner at the age of 13 months for exploration of cyanosis. The interview with the parents revealed that the mother worked in the manufacture of jewellery. The infant diet included vegetable purees containing carrots stored for more than 24 hours. The physical examination found normal weight, height and head circumference. She had cyanosis (figures 1 and 2). Cardiac and pulmonary auscultation were normal. The neurological examination was normal. Oxygen saturation was $94 \%$ in room air (she was crying). Chest X-ray and cardiac ultrasound were normal. The blood cell count showed polycythemia at $6490000 / \mathrm{mm}^{3}$, hemoglobin level was $12.7 \mathrm{~g} / \mathrm{dL}$. Electrophoresis of hemoglobin was normal. Renal and hepatic status were normal. Methemoglobinemia was considered, the methemoglobin level was measured at $39.4 \%$ thus confirming the diagnosis. A specialized investigation concerning the products handled by the mother excluded a toxic cause. The correction of the methods of preparation and conservation of the diet did not improve the cyanosis. The diagnosis of recessive congenital methemoglobinemia type I was strongly suspected. The determination of the enzymatic activity of NADH cytochrome b5 reductase 
and DNA sequencing are not available in Tunisia. Our patient received an intravenous infusion of $1.2 \mathrm{mg}$ per $\mathrm{kg}$ of methylene blue (MB) after eliminating glucose 6 dehydrogenase deficiency. Cyanosis disappeared immediately (figures 3 and 4). The methemoglobin level dropped to $2.6 \%$. Dietary measures were explained to parents. Four days after the medication, cyanosis reappeared, the methemoglobin level increased to $38.4 \%$. The patient received a second intravenous infusion of $\mathrm{MB}$ and then was put on vitamin $\mathrm{C}$ at a dose of 500 mg per day orally. After a 6 months follow-up and vitamin $\mathrm{C}$ treatment, there was a clear improvement. She has mild cyanosis on exercise. Methemoglobin level was $10.9 \%$. She showed no side effects of treatment.

Discussion:Methemoglobinemia is a condition due to an excessive formation of methemoglobin. In this form of hemoglobin, ferrous iron $\left(\mathrm{Fe}^{++}\right)$is oxidized to its ferric form $\left(\mathrm{Fe}^{+++}\right)$. On the one hand, MetHb is unable to bind oxygen and, on the other hand, it increases the affinity of other forms of hemoglobin for oxygen, thus causing a left shift in the oxygen dissociation curve. These phenomena contribute to a reduction in the delivery of oxygen to tissues, hypoxemia and cyanosis (1-2). There are three forms of methemoglobinemia: the acquired form following exposure to an oxidizing agent and this is the most common form. It is reversible by discontinuation of the offending agent. The second form is hemoglobin $\mathrm{M}$ disease, due to the presence of an abnormal hemoglobin: hemoglobin $\mathrm{M}$. The third and rarest form is congenital recessive methemoglobinemia CMR $(1,3)$. It is due to an enzyme deficiency in NADH cytochrome b5 reductase. This enzyme is responsible for the reduction of methemoglobin to deoxyhemoglobin. This enzyme is encoded by a gene located on 22q13 (4-6). Two forms of this enzyme are known: the soluble form present exclusively in erythrocytes and the membrane-bound form present in all tissues. There are two types of CMR: type I and type II. Type I is usually benign, the enzyme deficiency is limited to red blood cells. Clinically, the patient presents cyanosis without neurological disorders. In type II, the enzyme deficiency is generalized to all tissues and involves both forms. Cyanosis is associated with severe neurological impairment which onsets by the age of 6 to 9 months. The long term prognosis is poor due to swallowing distubances $(3,7)$. The diagnosis of methemoglobinemia is suspected by a "chocolate" color of the arterial blood. It is confirmed by the presence of a high MetHb level (above 1 to $3 \%$ ). The activity of NADH cytochrome b5 reductase is measured spectrophotometrically. Molecular analysis of the cytochrome b5 reductase gene determines mutations. Congenital recessive methemoglobinemia type I is associated with amino acid substitution mutations, whereas CMR type II is associated with nonsense mutations and deletions (4-5). Precise prevalence is unknown. It is estimated at 1 per 100000. A higher prevalence (47 per 100000) has been reported by Burtseva et al, who collected 43 cases of CRM in the Sakha Republic (6). For the management of CRM , the eviction of oxidative products is necessary. The available treatments are: methylene blue, ascorbic acid and riboflavin. Methylene blue is given intravenously in a dose of 1 to $2 \mathrm{mg} / \mathrm{kg}$. Response and improvement of cyanosis are rapid. Before treatment with MB, it is necessary to eliminate an associated G6PD deficiency because MB has an oxidant potential and can induce hemolysis in this case (1) . Methylene blue can be prescribed orally as maintenance therapy (3, 8-10). Ascorbic acid directly reduces methemoglobin but at a slow rate. Il was used by several teams for the treatment of CRM (1, 3, 8-9). Also, since the 1980s, high doses of riboflavin (120 mg/day) has been successfully prescribed in some patients (11). In congenital recessive methemoglobinemia type II, there are no evidences that treatments are effective on the neurological impairment (10).

\section{CONCLUSION:}

Recessive congenital methemoglobinemia is a rare condition. The constant symptom is cyanosis which can cause confusion with congenital heart diseases especially in children and so delay the diagnosis. Congenital recessive methemoglobinemia type I is responsible for cosmetic damage while the type II is severe neurological dysfunction. The treatment is based on the eviction of oxidants and intravenous methylene blue as an attack

treatment. The maintenance treatment is not consensual, the physian may use methylene blue, ascorbic acid or oral riboflavin.

\section{REFERENCES:}

1. Khade H, Raju U, Deshmukh T, Srivastav G, Kadiri V. NEONATAL CONGENITAL METHEMOGLOBINEMIA-. 
2. Tasci C, Nevruz O, Candir N, Bilgic H. A methemoglobinemia case who was previously diagnosed and treated as asthma. Respiratory Medicine Case Reports 2012;6:11-2.

3. Aslan D, Turkoz-Sucak G, Percy MJ. Recessive congenital methemoglobinemia in immediate generations. Turk J Pediatr 2016;58:113-5.

4. Fermo E, Bianchi P, Vercellati C, Marcello AP, Garatti M, Marangoni O, et al. Recessive hereditary methemoglobinemia: two novel mutations in the NADH-cytochrome b5 reductase gene. Blood Cells, Molecules, and Diseases 2008;41:50-5.

5. Kugler W, Pekrun A, Laspe P, Erdlenbruch B, Lakomek M. Molecular basis of recessive congenital methemoglobinemia, types I and II: Exon skipping and three novel missense mutations in the NADHcytochrome b5 reductase (diaphorase 1) gene. Human mutation 2001;17:348-.

6. Burtseva TE, Ammosova TN, Protopopova NN, Yakovleva SY, Slobodchikova MP. Enzymopenic Congenital Methemoglobinemia in Children of the Republic of Sakha (Yakutia). J Pediatr Hematol Oncol 2017;39:42-5.

7. Schwartz L, Franck P, Debruille C, Olivier J, Vigneron C, editors. Methémoglobinémie congénitale récessive: une cause rare de cyanose du nouveau-né. Annales de Biologie Clinique; 2005.

8. Da-Silva SS, Sajan IS, Underwood JP. Congenital methemoglobinemia: a rare cause of cyanosis in the newborn - a case report. Pediatrics 2003;112:e158-e61.

9. Bennaoui F, Draiss G, Bourrous M, Bouskraoui M. La méthémoglobinémie congénitale: à propos d'un cas. Journal de pediatrie et de puericulture 2010;23:198-200.

10. Cooper MS, Randall M, Rowell M, Charlton M, Greenway A, Barnes C. Congenital Methemoglobinemia Type II-Clinical Improvement with Short-Term Methylene Blue Treatment. Pediatr Blood Cancer 2016;63:558-60.

11. Hirano M, Matsuki T, Tanishima K, Takeshita M, Shimizu S, Nagamura Y, et al. Congenital methaemoglobinaemia due to NADH methaemoglobin reductase deficiency: successful treatment with oral riboflavin. British journal of haematology 1981;47:353-9. 


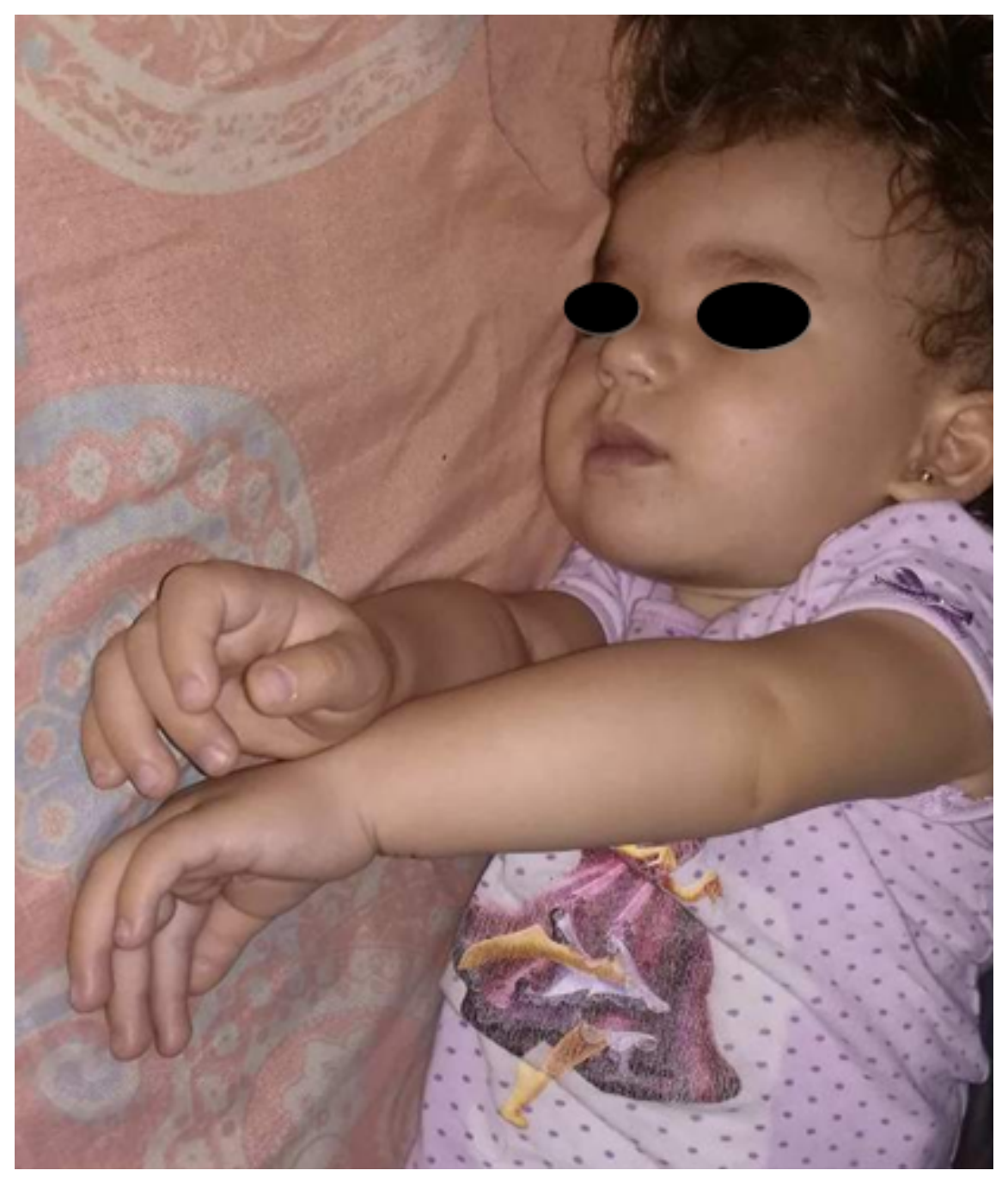




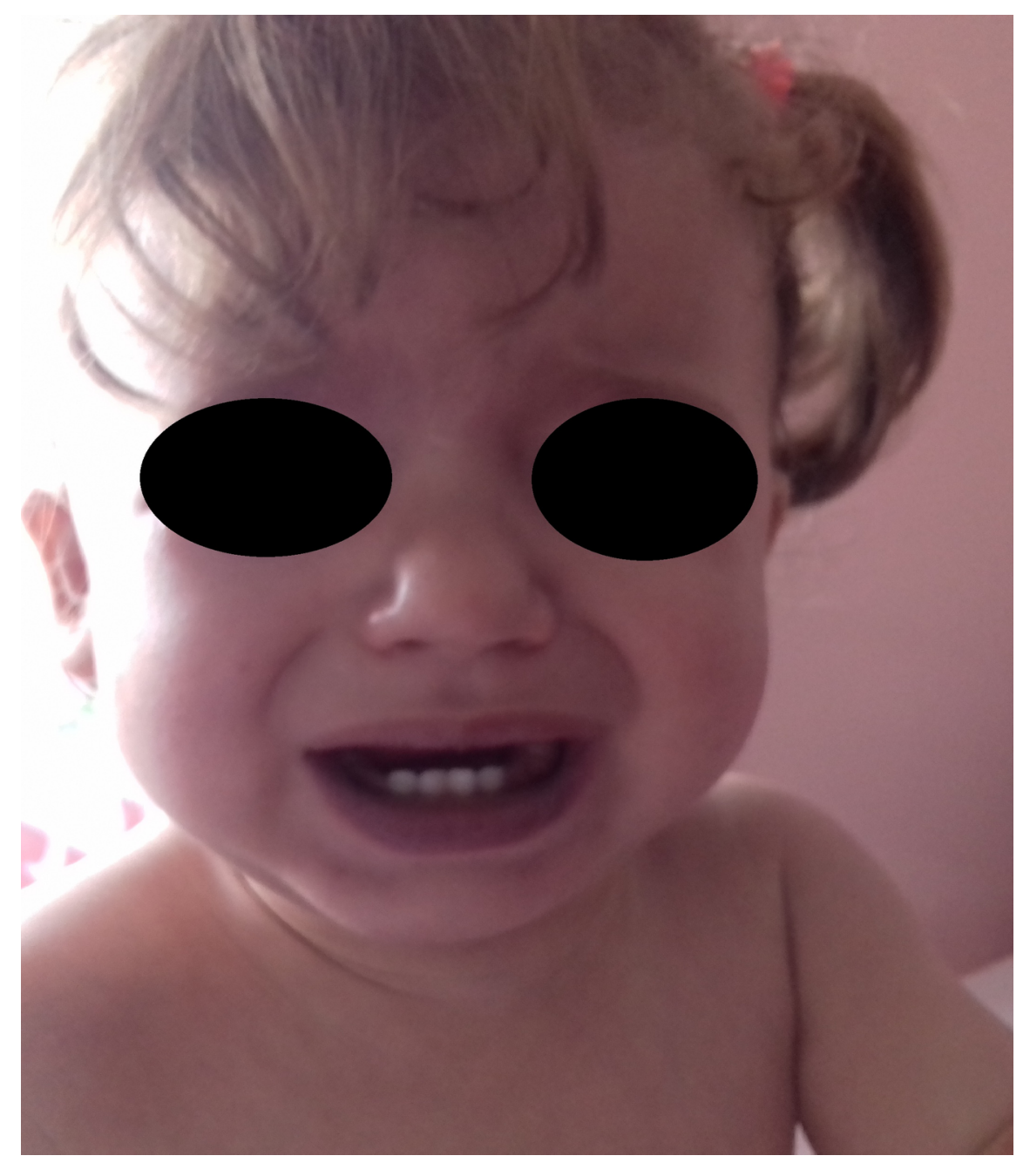




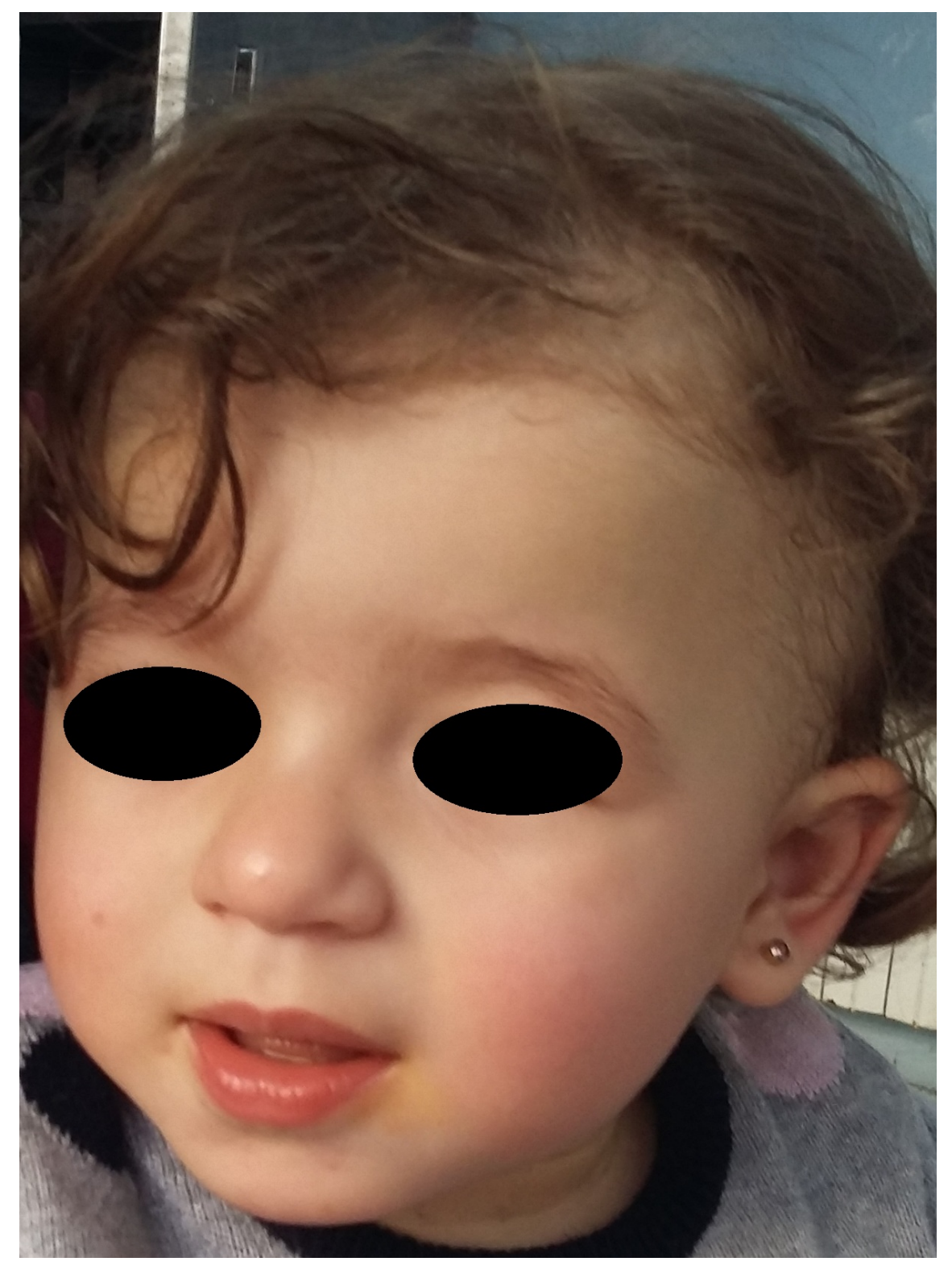




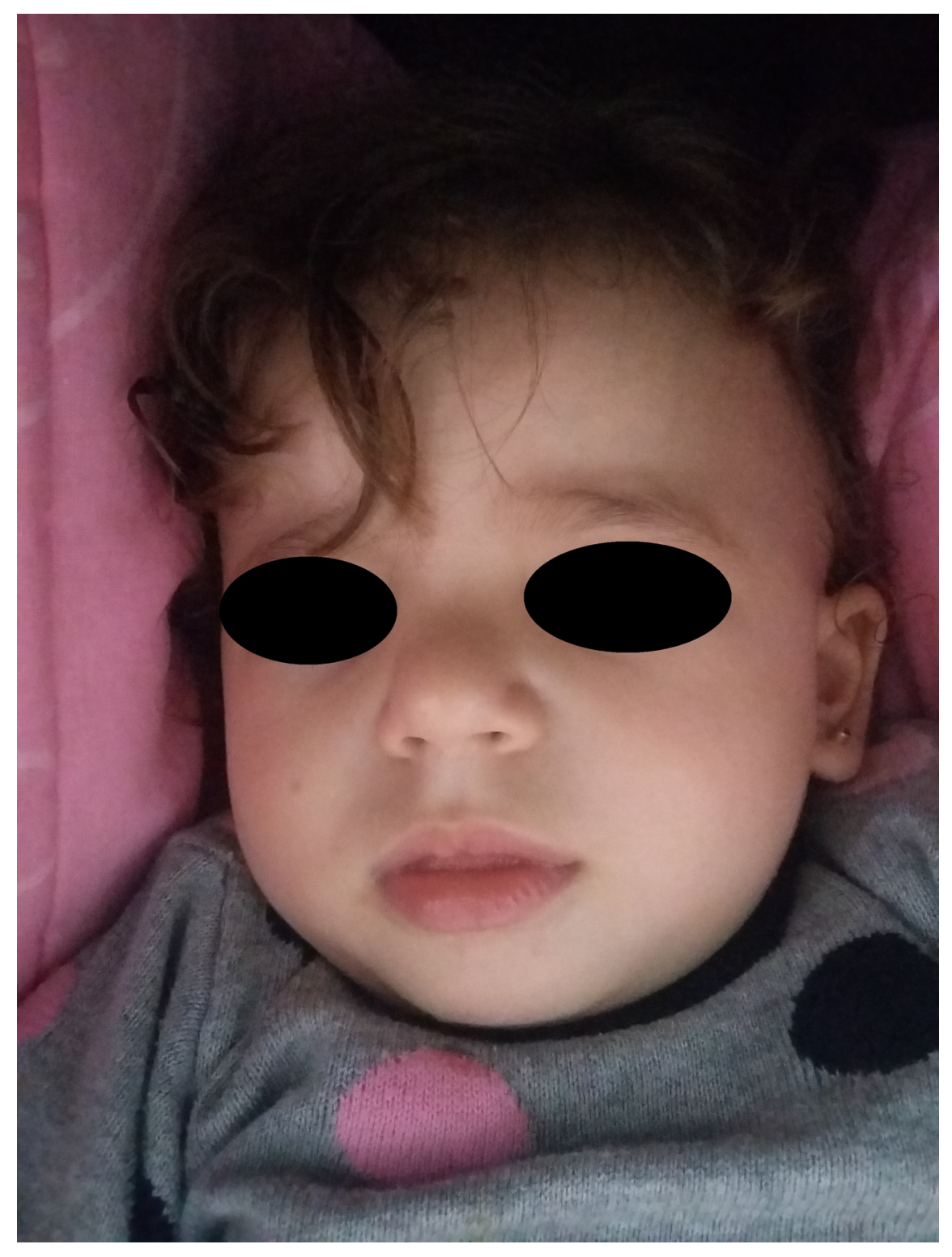

